\title{
Über das Verhalten des Salmiaks bei der Temperatur des Wasserbades.
}

\author{
Von \\ K. KraUt.
}

Bei Bestimmung der Alkalien in Form von Chloralkalimetallen plege ich die Lösung der Chloralkalien in einer grofsen Platinschale zu verdampfen, den trockenen Rückstand mit Hülfe eines Platinspatels in einen Tiegel zu bringen und den an den Wänden der Schale hängenden Rest in Wasser zı lösen. Wird diese Lösung nach Zusatz von etwa $0.5 \mathrm{~g}$ Salmiak in derselben Schale verdampft, das zurückbleibende trockene Gemenge von viel Salmiak mit wenig Chloralkalien in gleicher Weise in den Tiegel übergeführt und der bleibende Rest zum zweiten und dritten Male ebenso mit Salmiak behaudelt, so gelingt es, die Chloralkalien so vollständig aus der Schale zu entfernen, daf́s diese nach schwachem Glühen keinen Rückstand erkennen lälst und keine Gewichtszunahme zeigt. Andererseits ist das Verjagen des Salmiaks aus dem völlig trockenen Gemenge um vieles leichter ohne Verlust auszuführen, als das Austrocknen der beim Verdampfen einer salmiakfreien Lösung zurückbleibenden Chloralkalien in einem verhältnismäfsig kleinen Tiegel.

Als diese Operationen in einer Platinschale von $12.5 \mathrm{~cm}$ Durchmesser und $6 \mathrm{~cm}$ Höhe ausgeführt wurden, die $2 \mathrm{~cm}$ tief in das Wasserbad eintauchte, zeigte sich über dem Salzgemenge eine blanke, spiegelnde Zone, oberhalb derselben dagegen ein gleichmälsiger, dünner und lockerer Anflug, der auf Verflüchtigung des Salmiaks im Wasserbade, genauer auf Dissoziation, Wiedervereinigung der Dissoziationsprodukte und Verdichtung des neu gebildeten Salmiaks an den kïlteren Stellen der Schale deutete. Dafs eine solche Verflüchtigung in der That eintritt, zeigt der Verlauf des folgenden von Herrn O. Schultze ausgeführten Versuches.

$1.3408 \mathrm{~g}$ Salmiak wurden in Wasser gelöst, zur Trockne verdunstet und fünf Stunden in der angegebenen Weise im Wasserbade 
erhitzt. Die zurückbleibenden $1.3108 \mathrm{~g}$ Salmiak verloren bei weiterem Erhitzen im Wasserbade in

$\begin{array}{llllrrrrr}\text { Stunden } & 11 & 22 & 29 & 41 & 56 & 89 & 199 & 269 \\ \text { Milligramm } & 12 & 67 & 95.5 & 125 & 173 & 262 & 508 & 641\end{array}$

oder in je einer Stunde

$$
\begin{array}{lllllllll}
\text { Milligramm } & 1.09 & 3.01 & 3.29 & 3.05 & 3.09 & 2.91 & 2.55 & 2.48
\end{array}
$$

an Gewicht. Im ganzen hatten sich 48.9 Prozent des angewandten Salmiaks verflüchtigt. Ein ganz gleichmäfsiger, stets der Dauer des Erhitzens entsprechender Verlust ist nicht zu erwarten, da der Salmiak zu Anfang einen gröfseren, später einen kleineren Teil des Bodens der Platinschale bedeckt.

Auch wenn man eine wässerige Salmiaklösung in einem Glaskolben zur Trockne verdampft und den nach dreistündigem Erhitzen an der Luftpumpe bleibenden Rückstand 1ら Stunden im bedeckten Wasserbade in der Weise weiter erhitzt, dafs der Kolben vom Dampfe umspült wird, so bildet sich am herausragenden Halse des Kolbens ein deutliches Sublimat von Salmiak. Die $3 \mathrm{mg}$ oder 0.14 Prozent der angewandten Menge betragende Gewichtsabnahme mag bei dieser Versuchsanstellung durch Einwirkung des Wassers auf den Kolben bedingt sein.

Schon Fresenids' ${ }^{\mathfrak{A}}$ beobachtete, dafs von 100 Teilen Salmiak nach dem Auflösen in Wasser, Abdampfen und halbstündigem Trocknen im Wasserbade nur 99.69 Teile wiedererhalten wurden, aber der gezogene Schlufs ${ }^{2}$ : „Bei $100^{\circ}$ verliert der Salmiak nichts oder fast nichts an seinem Gewicht" bedarf nach unserem Versuche einer Einschränkung. Bei Fitrıgs Dissoziation des Salmiaks in wässeriger Lösung handelt es sich um andere Verhältnisse, als bei dem hier besehriebenen Versuche.

1 Quantitative Analyse, 6. Aufl. 2, 800. - " Daselbst 1, 150.

S Lieb. Ann. 128, 189.

Hannover, September 1893.

Bei der Redaktion eingegangen am 26. September 1893. 